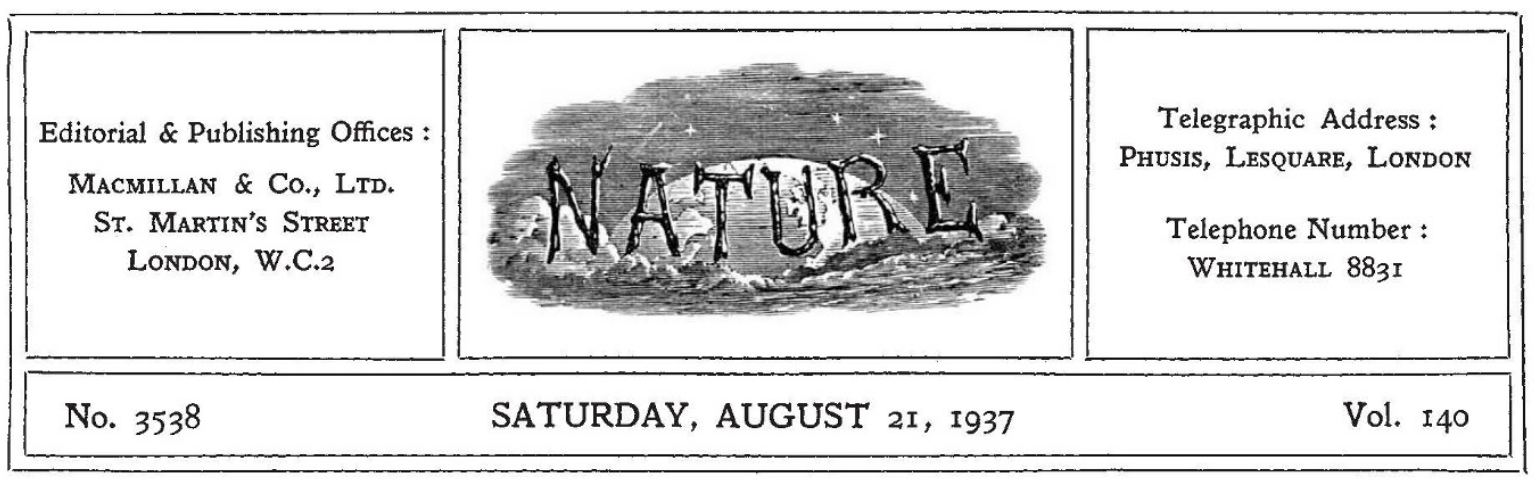

\title{
Milk Supply and National Health
}

\section{A}

FEATURE of the present-day interest in nutrition is the number of unofficial organizations which have sprung up with the object, by propaganda and other means, of directing attention to what is naturally and properly considered to be a matter of immediate public concern, and of stimulating the Government to take action on recommendations regarding nutritional needs which have been made by expert committees of the League of Nations, the Ministry of Health and other authoritative bodies.

Active among these organizations is the Children's Minimum Council-a non-party body the aim of which is to secure that no child shall, by reason of the poverty of its parents, be deprived of at least the minimum of food and other requirements necessary for full health. Undeniably, widespread damage is caused to our national health by malnutrition during pregnancy and lactation and in the early years of childhood. Undeniably, also, inadequate family means among a large section of our population is the chief contributory factor to the existence of this state of affairs. Such is proved by the recent surveys of Orr, M'Gonigle, Rowntree and others.

There is much that is still controversial regarding the right nutrition of our people ; but for those who seek an early improvement in existing conditions there is one guiding principle which may be followed without fear of contradiction or misdirection. It is the indisputable value of milk for nursing mothers and children.

In a recent memorandum on "Milk for Mothers and Children under Five", the Children's Minimum Council stresses the case for cheap milk. Expert Government committees have now unanimously declared that the desirable daily amount of milk for children is from one to two pints, for expectant and nursing mothers about two pints, and for other adult members of the community half a pint. At the present average prices, a family in which there are three children taking, say, one and a half pints a day each, an expectant mother taking two pints, and a father taking half a pint, would have an average milk bill of $13 s$. $3 d$. a week. Such an expenditure is, of course, quite beyond the means of working-class families with dependent children.

Consumption of milk in working-class households is far below the amounts regarded as desirable. Statistics from all over the country show how consumption drops with falling income and with an increasing number of children in the household. Many children get little or no fresh milk. For example, a survey of more than thirteen thousand school children in the Glasgow area showed that 57. 7 per cent did not drink milk at all.

The proposal of the Children's Minimum Couneil is that milk should be made available at $1 \frac{1}{2} d$. a pint for expectant and nursing mothers and children under school age in families covered by National Health Insurance or of equivalent economic status. Both producers and distributors should be asked to make some concession in their prices for milk supplied under the scheme, and whatever subsidy is thereafter needed to bring the price down to $1 \frac{1}{2} d$. a pint should be paid by the national Exchequer. It is estimated that there are in Great Britain about three and a half million expectant and nursing mothers and children under five. The Council argues that a yearly Government subsidy of just over one and a half million pounds would suffice to provide for an annual distribution of eighty million gallons of cheap milk among that number. This is 
on the assumption that their orders for the milk would average half a pint per head per day.

Any scheme which attempts to break down the price barrier preventing an adequate consumption of milk by those who most stand in need of it deserves our attention. Nevertheless, however laudable in itself, this new scheme is but another expedient (of which there are already three in existence) to remedy an evil the root cause of which lies much deeper than the mere inability of people to pay for milk. Various State-aided schemes for the provision of cheap milk to mothers and children are already in operation under the Public Health Act of 1936, the Education Act of 1921 and the Milk Act of 1934. Admittedly there are defects and anomalies in these schemes; but another will only bring confusion to an already complicated position and further increase the administrative difficulties of our already overburdened public health serviceș.

The case requires more drastic handling, and demands a fundamental change in the whole statutory position which at present governs the production and marketing of milk. In the past, the Government has tended to serve the economic interests of producers at the expense of the health interests of consumers. While no one will deny a fair return to the producer, it is out of all pro. portion that the interests of 175,000 producers should come before those of the ten million children on whose health the future of the country depends. The time has come when the Government must take a comprehensive view, and, without fear or favour, design a unified milk policy to meet the needs of the whole community.

\section{Genetics and Plant Breeding in the U.S.S.R.}

$\mathrm{T}$ HE fourth session of the Lenin Academy of Agricultural Sciences, held in Moscow at the end of 1936, witnessed a determined campaign against genetics as the main basis of scientific plant breeding ${ }^{1}$. It is only now, however, that detailed reports of some of the speeches made at the session are available, while further light is thrown upon the controversy by recent Soviet publications.

The attack was opened by a group of plantbreeding experts headed by T. D. Lysenko, a member of the Odessa Institute for Selection and Genetics. The main ideas of Lysenko do not appear to have been published in a scientific form, but they are expressed in a popular pamphlet ${ }^{2}$ and in his speech at the session of the Academy of Agricultural Sciences ${ }^{3}$. They are based on no lesser, and no later, authority than that of Charles Darwin, whose teachings according to Lysenko "were unable to blossom out properly in bourgeois countries. The best Darwinists in capitalistic countries, as for example Burbank in America, as well as our revolutionaries-biologists K. A. Timiriazev and I. V. Michurin in the Czar's Russia, were lone fighters." The works and theories of de Vries, Johannsen, Bateson, Morgan, are dismissed on the strength of a few quotations from their writings, suggesting their critical attitude to some of Darwin's ideas, all of which are held by Lysenko to be the last word in biology.
The actual controversy is centred around two points of practical plant breeding. One concerns the problem of crossing and selection of selffertilizing pure line plants. According to Lysenko, pure lines if cultivated for a long time are liable to degeneration. This can be prevented, and the line even improved, by artificial cross-fertilization within the variety. "Small field experiments" made at Odessa with some varieties of wheat have shown an increase in the yield from cross-fertilized seeds, and this was taken to be sufficient to consider the method ready for immediate introduction into practice. About 10,000 farmers on 2,000 collective farms were instructed to sterilize wheat plants by cutting stamens to prevent self-fertilizstion. As a result, $500-1,000 \mathrm{gm}$. of cross-fertilized seeds were obtained on each farm. "If it happens that the seeds from intra-varietal crossing should be of higher quality, should produce plants with greater yield .... there will be no obstacle to 8 rapid transformation of a kilogram of seeds on each farm into tens of tons". Since Lysenko is also practically certain (although without apparent data) that the improved plants will be more resistant to winter frosts, he urged the Academy to pay serious attention to the question of the immediate necessity of introducing the method of cross-fertilization on "at least 50-70 thousands of collective farms". 